\title{
Stereotactic body radiation therapy for low- and low-intermediate-risk prostate cancer: is there a dose effect?
}

\author{
Alan J. Katz ${ }^{1}{ }^{*}$, Michael Santoro ${ }^{1}$, Richard Ashley ${ }^{2}$ and Ferdinand Diblasio ${ }^{3}$ \\ 1 Flushing Radiation Oncology, Flushing, NY, USA \\ ${ }^{2}$ North Shore Long Island Jewish Medical Center, New Hyde Park, NY, USA \\ ${ }^{3}$ Mount Sinai Medical Group, Huntington, NY, USA
}

\section{Edited by:}

Sean Collins, Georgetown University Hospital, USA

\section{Reviewed by:}

Peter B. Schiff, NYU School of Medicine, USA

Joshua Silverman, New York University Medical Center, USA Robert Meier, Swedish Radiosurgery Center, USA

Debra Freeman, Naples Radiation Oncology, USA

\section{*Correspondence}

Alan J. Katz, Flushing Radiation Oncology, 145 Overlook Avenue, Great Neck, NY 11021, USA. e-mail: akatzmd@msn.com
This study examines the efficacy and toxicity of two stereotactic body radiation therapy (SBRT) dose regimens for treatment of early prostate cancer. Forty-one patients treated with $35 \mathrm{~Gy}$ were matched with 41 patients treated with $36.25 \mathrm{~Gy}$. Both patient groups received SBRT in five fractions over five consecutive days using the CyberKnife. Each group had 37 low-risk patients and 4 intermediate-risk patients. No statistically significant differences were present for age, prostate volume, PSA, Gleason score, stage, or risk between the groups. The dose was prescribed to the $83-87 \%$ isodose line to cover the prostate and a 5-mm margin all around, except $3 \mathrm{~mm}$ posteriorly. The overall median follow-up is 51 months (range, 45-58 months) with a median 54 and 48 months follow-up for the 35 and 36.25-Gy dose groups, respectively. One biochemical failure occurred in each group yielding a $97.5 \%$ freedom from biochemical failure. The PSA response has been favorable for all patients with a mean PSA of $0.1 \mathrm{ng} / \mathrm{ml}$ at 4-years. Overall toxicity has been mild with $5 \%$ late grade 2 rectal toxicity in both dose groups. Late grade 1 urinary toxicity was equivalent between groups; grade 2 urinary toxicity was $5 \%$ (2/41 patients) and 10\% (4/41 patients) in the 35-Gy and 36.25-Gy dose groups ( $p=0.6969)$, respectively. Overall, the highly favorable PSA response, limited biochemical failures, limited toxicity, and limited impact on quality of life in these low- to low-intermediate-risk patients are supportive of excellent long-term results for CyberKnife delivered SBRT.

Keywords: stereotactic body radiation therapy, prostate, dose, $\alpha / \beta$ ratio, CyberKnife

\section{INTRODUCTION}

As has been seen for other malignancies such as lung, liver, spine, and kidney (Svedman et al., 2008; Gagnon et al., 2009; Rusthoven et al., 2009; Martin and Gaya, 2010; Timmerman et al., 2010), evidence is rapidly accumulating that supports acceptable disease control and acute and late toxicity of stereotactic body radiotherapy (SBRT) for low-risk prostate cancer (Friedland et al., 2009; King et al., 2009; Bolzicco et al., 2010; Fuller et al., 2010; Jabbari et al., 2010; Katz et al., 2010; Meier et al., 2010; Boike et al., 2011; Freeman and King, 2011; Townsend et al., 2011). Indeed, initial studies on low-risk patients support SBRT's potential for clinical efficacy while limiting treatment-related morbidity and maintaining quality of life (QOL; Friedland et al., 2009; King et al., 2009; Katz et al., 2010). Longer-term results report $93 \%$ biochemical control at a median 5 years follow-up (Freeman and King, 2011). Additional publications with varying follow-up lengths, numbers of patients, and risk categories continue to support these findings (Bolzicco et al., 2010; Jabbari et al., 2010; Boike et al., 2011; Townsend et al., 2011). Furthermore, industry sponsored multiinstitution clinical studies have reported promising preliminary results (Fuller et al., 2010; Meier et al., 2010).

Stereotactic body radiotherapy delivers a large radiation dose in few fractions, typically four to five fractions of 7-10 Gy. This approach takes advantage of the prostate's low $\alpha / \beta$ ratio. While debate continues on the exact value of the $\alpha / \beta$ ratio evidence from a variety of sources suggest that the $\alpha / \beta$ ratio resides in the 1.4- to 1.5-Gy range (Brenner and Hall, 1999; Fowler et al., 2001, 2003; King and Fowler, 2001; Brenner et al., 2002). Furthermore, supporting evidence for this low $\alpha / \beta$ ratio value continues to accumulate; a recent report by Miralbell et al. (2011) concluded, based on seven datasets with over 5000 patients, that the $\alpha / \beta$ ratio for prostate cancer is $1.4 \mathrm{~Gy}$.

Given that increased dose, particularly for intermediate- and high-risk localized prostate cancer patients, has shown improved biochemical control and cause-specific survival for EBRT as well as intensity-modulated radiation therapy (IMRT) and brachytherapy treatments (Pollack et al., 2002; Kupelian et al., 2004; Zelefsky et al., 2006; Stone et al., 2010), the low $\alpha / \beta$ ratio of prostate cancer offers the opportunity, via hypofractionation, for even further dose escalation. Indeed, in the case of SBRT, assuming the prostate $\alpha / \beta$ ratio is $1.4-1.5$ Gy then the equivalent dose (EQD) for SBRT's hypofractionated dose schemes typically range from 90.15-140 Gy. Thus, SBRT offers a higher EQD1.8 than conventional fractionation schemes that reside around 70 Gy (Kuban et al., 2008), dose-escalated fractionation schemes ranging up to roughly 80 Gy (Zelefsky et al., 1998, 2006; Hanks et al., 2000), 
moderate hypofractionation (Kupelian et al., 2005) at $84.8 \mathrm{~Gy}$, and even "ultra-high" IMRT doses at 86.4 Gy (Cahlon et al., 2008). While long-term results are not yet available, the on-going favorable PSA and biochemical control results of SBRT delivered in the 90- to 96-Gy EQD1.8 range for low-risk patients are promising. As such, the purpose of this study is to examine the toxicity, PSA nadirs and 4-year efficacy of two dose regimens for CyberKnife delivered SBRT treatment of prostate cancer. Specifically, we examine SBRT delivery of a total dose of $35 \mathrm{~Gy}$ (EQD1.8 $91 \mathrm{~Gy}$ ) and 36.25 Gy (EQD1.8 96 Gy) both delivered in five daily fractions using the CyberKnife.

\section{MATERIALS AND METHODS PATIENTS AND TREATMENT}

Between April 2006 and July 2008, 304 patients with organconfined prostate cancer were treated with SBRT at Winthrop University Hospital in Mineola, NY, USA. All patients signed consent statements and were informed of the potential risks involved with this treatment. Institutional IRB-approval was obtained on the treatment protocol. Details of the treatment have been previously published (Katz et al., 2010). Briefly, a total dose of either 35 or $36.25 \mathrm{~Gy}$ was delivered in $5 \mathrm{~Gy}$ fractions over consecutive days using CyberKnife (Accuray Inc., Sunnyvale, CA, USA) SBRT. The planning target volume (PTV) equaled the prostate plus a $5-\mathrm{mm}$ margin ( $3 \mathrm{~mm}$ posteriorly). The dose was prescribed to the $83-87 \%$ isodose line covering $95 \%$ of the PTV. The D50 to bladder and rectum were to be less than $50 \%$ of Dmax, the D50 to the penile bulb was to be less than $45 \%$, there were no constraints on the urethra. All patients received a 1500-mg amifostine enema 15 min prior to each fraction after a bowel prep that included Dulcolax ${ }^{\circledR}$ (Boehringer Ingelheim, Germany) and a Fleet Enema. Four gold fiducials were tracked during each fraction, including translations and rotations, and beam aim automatically corrected when motion was detected. Each fraction was delivered in 45 min with two collimators using 140-170 beams.

\section{MATCHED PAIR}

For the purposes of this report, the low dose (35 Gy) patients were matched with the higher dose $(36.25 \mathrm{~Gy})$ patients by risk and in the order of treatment. Only patients who had not received neoadjuvant hormonal therapy were considered eligible for the pair matching. In addition, three patients in the 35-Gy group and three in the 36.25-Gy group who had died from causes other than prostate cancer were excluded from the pair matching. Specifically, each low dose patient that had not received neoadjuvant hormonal therapy was matched with a higher dose patient who had the same risk and who had not received neoadjuvant hormonal therapy. The higher dose patients were selected for pair matching in order from the time of treatment. This resulted in a match of 41 patients in each dose group.

\section{FOLLOW-UP AND STATISTICAL ANALYSIS}

All patients were scheduled for follow-up 3 weeks after final treatment, 4 months later and then every 6 months thereafter. PSA tests were performed 3 and 6 months after treatment, and every 6 months thereafter. QOL was assessed using the expanded prostate cancer index composite (EPIC) questionnaire (Wei et al., 2000) at every follow-up visit during the first year and every 12 months thereafter. Toxicity was assessed using the Radiation Therapy Oncology Group (RTOG) urinary and rectal toxicity scale (Cox et al., 1995) at every followup visit. Biochemical failure was assessed using the Phoenix definition (Roach et al., 2006). Statistical independence for patient characteristics was assessed for continuous variables using the Student's $t$-test whereas discrete variables were assessed using the Fisher's exact test. All statistical analysis was performed using Prism (GraphPad Software, Inc., La Jolla, CA, USA).

\section{RESULTS}

\section{MATCHED PAIR}

A total of 41 patients from each dose group were included in this analysis. No statistically significant differences were present for age, baseline PSA, Gleason score, prostate volume, stage, or risk between the two dose groups (Table 1). Specifically, each group had 37 low-risk patients (Gleason Score 6 and PSA $<10 \mathrm{ng} / \mathrm{ml}$ ) and 4 intermediate-risk patients (Gleason Score 7 or PSA $>10$ and $<20 \mathrm{ng} / \mathrm{ml}$ ). Median baseline PSAs were 5.46 and $5.52 \mathrm{ng} / \mathrm{ml}$ for the low- and intermediate-risk groups, respectively. Median ages were 70.2 and 69.8 years, respectively. The median number of positive cores in each group was 2 . The mean prostate volume was $48.23 \mathrm{cc}$ (range, $28-108 \mathrm{cc}$ ). Dose constraints were met with the mean D50's $42 \%$ of Dmax for the rectum/bladder and less than $40 \%$ of Dmax for the penile bulb. The mean dose to the testes was $5.1 \mathrm{~Gy}$.

Table 1 | Patient characteristics detailed by overall cohort and dose.

\begin{tabular}{|c|c|c|c|c|}
\hline Characteristic & All patients $(n=82)$ & 35 Gy group $(n=41)$ & $36.25 \mathrm{~Gy}$ group $(n=41)$ & $p$-Value \\
\hline Low-risk & 74 & 37 & 37 & 1 \\
\hline Intermediate risk & 4 & 4 & 4 & 1 \\
\hline T1c & 64 & 38 & 38 & 1 \\
\hline T2a & 6 & 3 & 3 & 1 \\
\hline Median prostate volume (cc) & $48.23,28-108$ & $49.05,28-108$ & $47.41,29-104$ & 0.821 \\
\hline
\end{tabular}




\section{CLINICAL OUTCOMES}

The overall median follow-up is 51 months (range, 45-58 months) with a median 54 months (range, 51-58 months) and 48 months (range, 45-52 months) follow-up for the 35-Gy and 36.25-Gy dose groups, respectively. The PSA response (Figure 1) has been favorable for all patients with a median PSA of 0.2, 0.1, and $0.1 \mathrm{ng} / \mathrm{ml}$ at 36,42 , and 48 months, respectively, with no statistically significant differences observed between the dose groups at latest follow-up $(p=0.8130)$ or as a function of time $(p=0.7704)$. To date, one biochemical failure has occurred in each dose group. For the $35-\mathrm{Gy}$ dose group a low-risk patient failed at 50 months. For the $36.25-\mathrm{Gy}$ dose group a low-risk patient failed at 36 months. Both patients had distant metastases. The resulting overall 4-year freedom from biochemical relapse is $97.5 \%$.

\section{TOXICITY AND QUALITY OF LIFE}

Late grade 2 rectal toxicity was $5 \%$ for both groups. Late grade 2 urinary toxicity, consisting of dysuria, urgency, and incontinence, occurred in $2 / 41(5 \%)$ patients for the 35-Gy group and in $4 / 41(10 \%)$ patients for the $36.25-G y$ group. Of those patients that were cystoscoped prostatic urethral inflammation was the cause of the symptoms. The differences in late grade rectal and

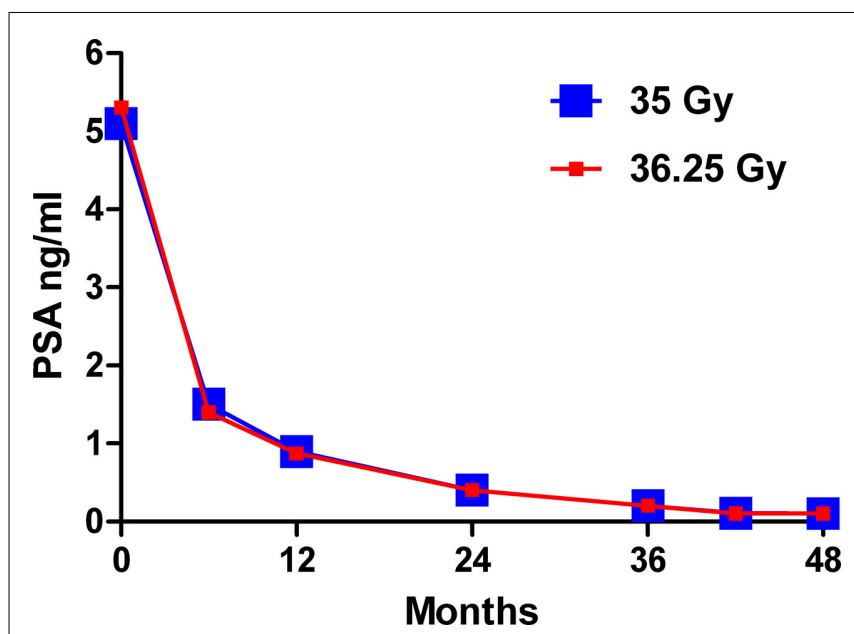

FIGURE 1 | Median PSA response over time for the 35-Gy (blue) and $36.25 \mathrm{~Gy}$ (red) dose groups. urinary toxicity were not statistically significant $(p=0.8987$ and $p=0.6969$, respectively). No grade 3 or 4 toxicities were observed. Table 2 summarizes all observed late toxicity.

Figure 2 plots the mean EPIC scores for bowel, urinary, and sexual QOL along with patient response rates for both dose groups. All mean EPIC QOL scores initially decreased. The mean bowel and urinary QOL scores subsequently returned to baseline values. No statistically significant differences over time were observed between dose groups for the mean bowel and sexual QOL, however, for the mean urinary QOL a small, but significant difference $(p=0.0001)$ was observed over time with the lower dose group having a better QOL. This difference dissipated over time; comparison of the mean urinary QOL scores for the two dose groups as a function of time at 36 and 48 months showed no significant difference $(p=0.4999)$.

\section{DISCUSSION}

This matched pair analysis shows that at 4 years follow-up, CyberKnife delivered SBRT produces highly promising clinical outcomes, overall limited toxicity and minimal impact on patient QOL, regardless of whether a total dose of 35 or 36.25 Gy was delivered for low- to low-intermediate-risk patients. While longer follow-up is needed to confirm the durability of the current clinical outcomes, these results are supportive of a low $\alpha / \beta$ ratio. Results from Cahlon et al. (2008) using ultra-high dose IMRT to $86.4 \mathrm{~Gy}$ yields even higher rates of control than seen with $81 \mathrm{~Gy}$ (Zelefsky et al., 2006). At 4 years median follow-up with $35 \mathrm{~Gy}$, the results in the current study show a similarly high freedom from relapse to the 98\% 4-year actuarial rates of Cahlon et al. (2008) and an even lower median PSA at $0.10 \mathrm{ng} / \mathrm{ml}$. If the $\alpha / \beta$ ratio is not $1.5 \mathrm{~Gy}$ but higher, say $3 \mathrm{~Gy}$, then the EQD1.8 at the $35 \mathrm{~Gy}$ dose would only be $72 \mathrm{~Gy}$. Yet, in order to achieve the results observed in this study, in comparison to those obtained with delivery of $86.4 \mathrm{~Gy}$, it is reasonable to assume a comparable or higher EQD1.8 was delivered. Indeed, with an $\alpha / \beta$ ratio of $1.5 \mathrm{~Gy}$, the total delivered dose of $35 \mathrm{~Gy}$ is equivalent to a EQD1.8 of about $91 \mathrm{~Gy}$, which is consistent with the observed rates of biochemical control.

The PSA nadirs reached in both groups of the current study are suggestive of excellent long-term outcomes (Fowler, 2005). An increasingly large body of data in the literature supports the predictive value of the PSA nadir (Grimm et al., 2001; Ray et al., 2006; Alcantara et al., 2007; Stock et al., 2009; Zelefsky et al., 2009; Lamb et al., 2011). Specifically, following an analysis of 742 patients treated with brachytherapy or external beam radiotherapy, Stock

Table 2 | Summary of RTOG late toxicity.

\begin{tabular}{|c|c|c|c|c|}
\hline & All patients ( $n=82$ ) & 35 Gy group $(n=41)$ & 36.25 Gy group $(n=41)$ & $p$-Value \\
\hline \multicolumn{5}{|c|}{ URINARY } \\
\hline Grade 0 & 72 & 37 & 35 & 0.6969 \\
\hline Grade 1 & 4 & 2 & 2 & \\
\hline Grade 2 & 6 & 2 & 4 & \\
\hline \multicolumn{5}{|l|}{ RECTAL } \\
\hline Grade 0 & 73 & 37 & 36 & 0.8987 \\
\hline Grade 1 & 5 & 2 & 3 & \\
\hline Grade 2 & 4 & 2 & 2 & \\
\hline
\end{tabular}


et al. (2009) found that the 5-year PSA value is prognostic. They further found that patients with a PSA value of less than $0.2 \mathrm{ng} / \mathrm{ml}$ were unlikely to undergo biochemical failure. Zelefsky et al. (2009) concluded that the 2-year PSA nadir is a predictor of long-term prostate cancer mortality. While the median follow-up in the present study is only 4 years, the median PSA is $0.1 \mathrm{ng} / \mathrm{ml}$ with $71 \%$ of patients having a PSA value of less than $0.2 \mathrm{ng} / \mathrm{ml}$. In fact, it appears that not all patients have reached their ultimate nadir, as their PSAs are still slowly dropping. These low PSA readings are comparable to those achieved with high-dose-rate (HDR) brachytherapy (Martinez et al., 2001, 2009), supporting the equivalence of these hypofractionated dose schemes with HDR. It also suggests that the results with the two dose schemes used in this study will not diverge over time.

In terms of toxicity, observed differences in urinary toxicity between the dose groups were not statistically significant; late grade 3-5 toxicity was not observed in either dose group. While 4/41 patients in the higher dose group exhibited late grade 2 urinary toxicity compared with $2 / 41$ patients in the lower dose group (grade 1 urinary toxicity was equal between groups), the small number of patients and relatively short follow-up does not allow firm conclusions regarding the effect of dose on toxicity. Still, an $\alpha / \beta$ ratio of $3 \mathrm{~Gy}$ for the urethra suggests that the higher dose could increase the rate of complications as the EQD1.8 rises from 72 to $78 \mathrm{~Gy}$. The potential for increased urinary toxicity at higher doses should encourage careful attention to dose constraints, and perhaps inclusion of urethral dose constraints. If biochemical control between dose groups remains comparable with longer follow-up, it may be possible to treat with the lower dose which may decrease the likelihood of urinary toxicity.

It should be emphasized that this study compares two doses that were prescribed identically, with daily fractions and coverage of the PTV at $83-87 \%$ of the Dmax. When comparing the relative benefits and toxicities of other doses used in other studies, one must be careful to discern how the dose prescription is defined. For instance, one must take into account that IMRT based plans will be more homogeneous, may impose less urethral dose and may deliver less dose to the gross tumor volume (GTV) than a CyberKnife SBRT plan that delivers the same dose to the PTV. Even when comparing different CyberKnife doses there is variability in how the dose prescription is defined. Specifically, in this study the prostate GTV received at least $7 \%$ more dose than the PTV, yielding respective doses of about 37.50 and $38.75 \mathrm{~Gy}$. In contrast, in a multi-institutional CyberKnife SBRT clinical study (Meier et al., 2010), the PTV is covered at 36.25 Gy, but the prostate GTV receives at least $40 \mathrm{~Gy}$. Even more confounding to direct comparisons is the HDR-like dosimetry used in some centers (Fuller, 2008; Jabbari et al., 2010) whereby the prescription dose is 38 Gy delivered in four fractions, but the delivered dose to the peripheral zone is much higher and the urethra is contoured and urethral dose constrained (Fuller, 2008; Jabbari et al., 2010). Also, in two recently published studies patients were treated every other day (King et al., 2009; Boike et al., 2011), which may impact the efficacy and toxicity due to repair that may take place in the 48 -h period between fractions. Thus, while comparing the reported toxicity and outcomes of various studies is important, it is equally important to note the differences in both prescription dose as well as the overall
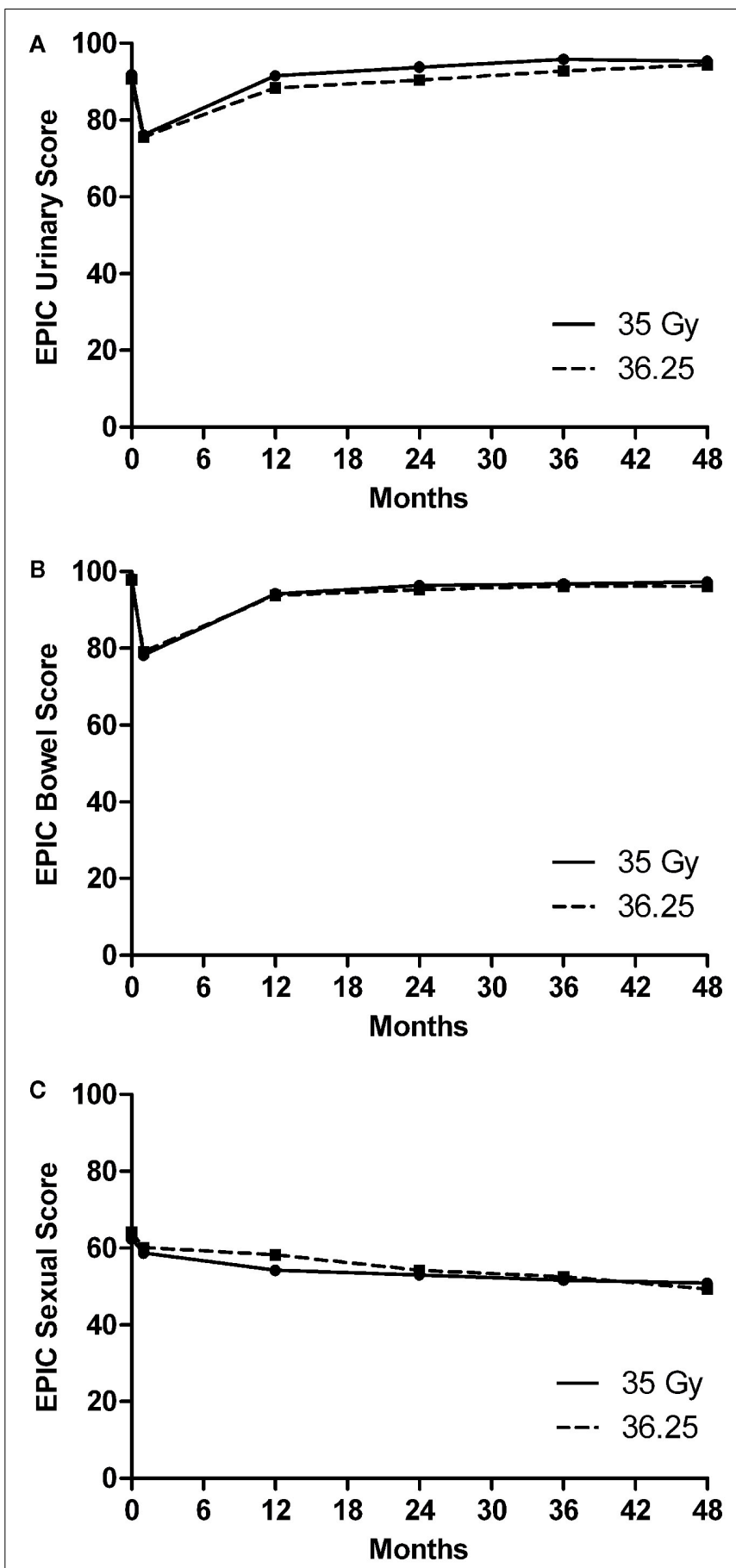

FIGURE 2 | Plots of mean EPIC quality of life over time from SBRT treatment for the $35-\mathrm{Gy}$ (solid line) and $36.25 \mathrm{~Gy}$ (dashed line) group for (A) urinary, (B) bowel, and (C) sexual function.

treatment planning and dose delivery since these factors can also affect the expected outcomes.

\section{CONCLUSION}

The highly favorable PSA response, limited biochemical failures, and overall limited toxicity and impact on QOL in these 
low- to low-intermediate-risk patients, obtained regardless of the dose delivered, are supportive of excellent long-term results for CyberKnife delivered SBRT. A small, non-significant increase in the rate of late grade 2 urethral toxicity, with no increase in grade 1 toxicity, was observed in the higher dose group, but no higher rate of biochemical disease free survival was seen. Further followup will be necessary to validate these observations with the current data and larger populations of patients with longer follow-up should be compared to confirm these findings. Nevertheless, it should be noted that such a trend would also be true for even higher delivered SBRT doses. That is, treatment regimes delivering total doses of 38 Gy in four fractions (Fuller et al., 2010), 40 Gy

\section{REFERENCES}

Alcantara, P., Hanlon, A., Buyyounouski, M. K., Horwitz, E. M., and Pollack, A. (2007). Prostatespecific antigen nadir within 12 months of prostate cancer radiotherapy predicts metastasis and death. Cancer 109, 41-47.

Boike, T. P., Lotan, Y., Cho, L. C., Brindle, J., Derose, P., Xie, X. J., Yan, J., Foster, R., Pistenmaa, D., Perkins, A., Cooley, S., and Timmerman, R. (2011). Phase I dose-escalation study of stereotactic body radiation therapy for low- and intermediaterisk prostate cancer. J. Clin. Oncol. 29, 2020-2026.

Bolzicco, G., Favretto, M. S., Scremin, E., Tambone, C., Tasca, A., and Guglielmi, R. (2010). Image-guided stereotactic body radiation therapy for clinically localized prostate cancer: preliminary clinical results. Technol. Cancer Res. Treat. 9, 473-477.

Brenner, D. J., and Hall, E. J. (1999). Fractionation and protraction for radiotherapy of prostate carcinoma. Int. J. Radiat. Oncol. Biol. Phys. 43, 1095-1101.

Brenner, D. J., Martinez, A. A., Edmundson, G. K., Mitchell, C., Thames, H. D., and Armour, E. P. (2002). Direct evidence that prostate tumors show high sensitivity to fractionation (low alpha/beta ratio), similar to late-responding normal tissue. Int. J. Radiat. Oncol. Biol. Phys. 52, 6-13.

Cahlon, O., Zelefsky, M. J., Shippy, A., Chan, H., Fuks, Z., Yamada, Y., Hunt, M., Greenstein, S., and Amols, H. (2008). Ultra-high dose (86.4 Gy) IMRT for localized prostate cancer: toxicity and biochemical outcomes. Int. J. Radiat. Oncol. Biol. Phys. 71, 330-337.

Cox, J. D., Stetz, J., and Pajak, T. F. (1995). Toxicity criteria of the Radiation Therapy Oncology Group (RTOG) and the European Organization for Research and Treatment of Cancer (EORTC). Int. J. Radiat. Oncol. Biol. Phys. 31, 1341-1346.

Fowler, J., Chappell, R., and Ritter, M. (2001). Is alpha/beta for prostate Oncol. Biol. Phys. 50, 1021-1031.

Fowler, J. F. (2005). The radiobiology of prostate cancer including new aspects of fractionated radiotherapy.

Fowler, J. F., Ritter, M. A., Chappell, R. J., and Brenner, D. J. (2003). What hypofractionated protocols should be tested for prostate cancer? Int. J. Radiat. Oncol. Biol. Phys. 56, 1093-1104.

Freeman, D. E., and King, C. R. (2011). Stereotactic body radiotherapy for low-risk prostate cancer: five-year outcomes. Radiat. Oncol. 6, 3.

Friedland, J. L., Freeman, D. E., Masterson-Mcgary, M. E., and Spellberg, D. M. (2009). Stereotactic body radiotherapy: an emerging treatment approach for localized prostate cancer. Technol. Cancer Res. Treat. 8 , 387-392.

Fuller, D. B. (2008). CyberKnife Radiosurgery For Low and Intermediate Risk Prostate Cancer: Emulating HDR Brachytherapy Dosimetry. Available at: http://clinicaltrials. gov/ct2/show/NCT00643617

Fuller, D. B., Mardirossian, G., Wong, D., and Mckellar, H. (2010). Prospective evaluation of stereotactic radiotherapy for low and intermediate risk prostate cancer: emulating HDR brachytherapy dose distribution. Int. J. Radiat. Oncol. Biol. Phys. 78, S358S359.

Gagnon, G. J., Nasr, N. M., Liao, J. J., Molzahn, I., Marsh, D., Mcrae, D., and Henderson, F. C. Sr. (2009). Treatment of spinal tumors using cyberknife fractionated stereotactic radiosurgery: pain and quality-oflife assessment after treatment in 200 patients. Neurosurgery 64, 297-306; discussion 306-297.

Grimm, P. D., Blasko, J. C., Sylvester, J. E., Meier, R. M., and Cavanagh, tumors really low? Int. J. Radiat. Acta Oncol. 44, 265-276.

in five fractions (Meier et al., 2010), and 50 Gy in five fractions (Boike et al., 2011) may well observe higher toxicity. The question is whether delivery of higher doses will result in a corresponding improvement in disease control or if further dose escalation is unwarranted in the population of low- to low-intermediate-risk organ confined prostate cancer patients.

\section{ACKNOWLEDGMENTS}

We gratefully acknowledge the editorial assistance of Pam Commike, Ph.D., Accuray Incorporated. The views expressed here are entirely the authors'; Accuray did not provide assistance with data collection, compilation, or interpretation.

W. (2001). 10-Year biochemical (prostate-specific antigen) control of prostate cancer with (125)I brachytherapy. Int. J. Radiat. Oncol. Biol. Phys. 51, 31-40.

Hanks, G. E., Hanlon, A. L., Pinover, W. H., Horwitz, E. M., Price, R. A., and Schultheiss, T. (2000). Dose selection for prostate cancer patients based on dose comparison and dose response studies. Int. J. Radiat. Oncol. Biol. Phys. 46, 823-832.

Jabbari, S., Weinberg, V. K., Kaprealian, T., Hsu, I. C., Ma, L., Chuang, C., Descovich, M., Shiao, S., Shinohara, K., Roach, M. III, and Gottschalk, A. R. (2010). Stereotactic body radiotherapy as monotherapy or postexternal beam radiotherapy boost for prostate cancer: technique, early toxicity, and PSA response. Int. J. Radiat. Oncol. Biol. Phys. (in press).

Katz, A. J., Santoro, M., Ashley, R., Diblasio, F., and Witten, M. (2010). Stereotactic body radiotherapy for organconfined prostate cancer. BMC Urol. 10, 1. doi:10.1186/1471-2490-10-1

King, C. R., Brooks, J. D., Gill, H., Pawlicki, T., Cotrutz, C., and Presti, J. C. Jr. (2009). Stereotactic body radiotherapy for localized prostate cancer: interim results of a prospective phase II clinical trial. Int. J. Radiat. Oncol. Biol. Phys. 73, 1043-1048.

King, C. R., and Fowler, J. F. (2001). A simple analytic derivation suggests that prostate cancer alpha/beta ratio is low. Int. J. Radiat. Oncol. Biol. Phys. 51, 213-214.

Kuban, D. A., Tucker, S. L., Dong, L., Starkschall, G., Huang, E. H., Cheung, M. R., Lee, A. K., and Pollack, A. (2008). Long-term results of the M. D. Anderson randomized doseescalation trial for prostate cancer. Int. J. Radiat. Oncol. Biol. Phys. 70, 67-74.

Kupelian, P., Kuban, D., Thames, H., Levy, L., Horwitz, E., Martinez, A., Michalski, J., Pisansky, T., Sandler, H., Shipley, W., Zelefsky, M., and
Zietman, A. (2005). Improved biochemical relapse-free survival with increased external radiation doses in patients with localized prostate cancer: the combined experience of nine institutions in patients treated in 1994 and 1995. Int. J. Radiat. Oncol. Biol. Phys. 61, 415-419.

Kupelian, P. A., Potters, L., Khuntia, D. Ciezki, J. P., Reddy, C. A., Reuther, A. M., Carlson, T. P., and Klein, E. A. (2004). Radical prostatectomy, external beam radiotherapy $<72 \mathrm{~Gy}$, external beam radiotherapy $>$ or $=72 \mathrm{~Gy}$, permanent seed implantation, or combined seeds/external beam radiotherapy for stage T1-T2 prostate cancer. Int. J. Radiat. Oncol. Biol. Phys. 58, 25-33.

Lamb, D. S., Denham, J. W., Joseph, D. Matthews, J., Atkinson, C., Spry, N. A., Duchesne, G., Ebert, M., Steigler, A., Delahunt, B., and D'este, C. (2011). A comparison of the prognostic value of early PSA test-based variables following external beam radiotherapy, with or without preceding androgen deprivation: analysis of data from the TROG 96.01 randomized trial. Int. J. Radiat. Oncol. Biol. Phys. 79, 385-391.

Martin, A., and Gaya, A. (2010). Stereotactic body radiotherapy: a review. Clin. Oncol. (R. Coll. Radiol.) 22, 157-172.

Martinez, A. A., Demanes, J., Vargas, C., Schour, L., Ghilezan, M. and Gustafson, G. S. (2009). Highdose-rate prostate brachytherapy: an excellent accelerated-hypofractionated treatment for favorable prostate cancer. Am. J. Clin. Oncol. 33, 481-488.

Martinez, A. A., Pataki, I., Edmundson, G., Sebastian, E., Brabbins, D. and Gustafson, G. (2001). Phase II prospective study of the use of conformal high-dose-rate brachytherapy as monotherapy for the treatment of favorable stage prostate cancer: a feasibility report. Int. J. Radiat. Oncol. Biol. Phys. 49, 61-69. 
Meier, R., Beckman, A., Kaplan, I., Mohideen, N., Shieh, E., Henning, G., Walz, B., Cotrutz, C., and Sanda, M. (2010). Stereotactic radiotherapy for organ-confined prostate cancer: early toxicity and quality of life outcomes from a multi-institutional trial. Int. J. Radiat. Oncol. Biol. Phys. 78, S57.

Miralbell, R., Roberts, S. A., Zubizarreta, E., and Hendry, J. H. (2011). Dosefractionation sensitivity of prostate cancer deduced from radiotherapy outcomes of 5,969 patients in seven international institutional datasets: alpha/beta=1.4 (0.9-2.2) Gy. Int. J. Radiat. Oncol. Biol. Phys. (in press).

Pollack, A., Zagars, G. K., Starkschall, G., Antolak, J. A., Lee, J. J., Huang, E., Von Eschenbach, A. C., Kuban, D. A., and Rosen, I. (2002). Prostate cancer radiation dose response: results of the M. D. Anderson phase III randomized trial. Int. J. Radiat. Oncol. Biol. Phys. 53, 1097-1105.

Ray, M. E., Thames, H. D., Levy, L. B., Horwitz, E. M., Kupelian, P. A., Martinez, A. A., Michalski, J. M., Pisansky, T. M., Shipley, W. U., Zelefsky, M. J., Zietman, A. L., and Kuban, D. A. (2006). PSA nadir predicts biochemical and distant failures after external beam radiotherapy for prostate cancer: a multi-institutional analysis. Int. J. Radiat. Oncol. Biol. Phys. 64, 1140-1150.

Roach, M. III, Hanks, G., Thames, H. Jr., Schellhammer, P., Shipley, W. U., Sokol, G. H., and Sandler, H.
(2006). Defining biochemical failure following radiotherapy with or without hormonal therapy in men with clinically localized prostate cancer: recommendations of the RTOGASTRO Phoenix Consensus Conference. Int. J. Radiat. Oncol. Biol. Phys. 65, 965-974.

Rusthoven, K. E., Kavanagh, B. D., Cardenes, H., Stieber, V. W., Burri, S. H., Feigenberg, S. J., Chidel, M. A., Pugh, T. J., Franklin, W., Kane, M., Gaspar, L. E., and Schefter, T. E. (2009). Multi-institutional phase I/II trial of stereotactic body radiation therapy for liver metastases. J. Clin. Oncol. 27, 1572-1578.

Stock, R. G., Klein, T. J., Cesaretti, J. A., and Stone, N. N. (2009). Prognostic significance of 5-year PSA value for predicting prostate cancer recurrence after brachytherapy alone and combined with hormonal therapy and/or external beam radiotherapy. Int. J. Radiat. Oncol. Biol. Phys. 74, 753-758.

Stone, N. N., Stock, R. G., Cesaretti, J. A., and Unger, P. (2010). Local control following permanent prostate brachytherapy: effect of high biologically effective dose on biopsy results and oncologic outcomes. Int. J. Radiat. Oncol. Biol. Phys. 76, 355-360.

Svedman, C., Karlsson, K., Rutkowska, E., Sandstrom, P., Blomgren, H., Lax, I., and Wersall, P. (2008). Stereotactic body radiotherapy of primary and metastatic renal lesions for patients with only one functioning kidney. Acta Oncol. 47, 1578-1583.

Timmerman, R., Paulus, R., Galvin, J., Michalski, J., Straube, W., Bradley, J., Fakiris, A., Bezjak, A., Videtic, G., Johnstone, D., Fowler, J., Gore, E. and Choy, H. (2010). Stereotactic body radiation therapy for inoperable early stage lung cancer. JAMA 303, 1070-1076.

Townsend, N. C., Huth, B. J., Ding, W., Garber, B., Mooreville, M., Arrigo, S., Lamond, J., and Brady, L. W. (2011). Acute toxicity after cyberknife-delivered hypofractionated radiotherapy for treatment of prostate cancer. Am. J. Clin. Oncol. 34, 6-10.

Wei, J. T., Dunn, R. L., Litwin, M. S., Sandler, H. M., and Sanda, M. G. (2000). Development and validation of the expanded prostate cancer index composite (EPIC) for comprehensive assessment of healthrelated quality of life in men with prostate cancer. Urology 56, 899-905.

Zelefsky, M. J., Chan, H., Hunt, M., Yamada, Y., Shippy, A. M., and Amols, H. (2006). Longterm outcome of high dose intensity modulated radiation therapy for patients with clinically localized prostate cancer. J. Urol. 176, 1415-1419.

Zelefsky, M. J., Leibel, S. A., Gaudin, P. B., Kutcher, G. J., Fleshner, N. E., Venkatramen, E. S., Reuter, V.
E., Fair, W. R., Ling, C. C., and Fuks, Z. (1998). Dose escalation with three-dimensional conformal radiation therapy affects the outcome in prostate cancer. Int. J. Radiat. Oncol. Biol. Phys. 41, 491-500.

Zelefsky, M. J., Shi, W., Yamada, Y., Kollmeier, M. A., Cox, B., Park, J., and Seshan, V. E. (2009). Postradiotherapy 2-year prostate-specific antigen nadir as a predictor of longterm prostate cancer mortality. Int J. Radiat. Oncol. Biol. Phys. 75, 1350-1356.

Conflict of Interest Statement: Dr. Katz has received speaker's honoraria from Accuray, Inc., Sunnyvale, CA, USA.

Received: 28 June 2011; accepted: 15 November 2011; published online: 05 December 2011.

Citation: Katz AJ, Santoro M, Ashley $R$ and Diblasio F (2011) Stereotactic body radiation therapy for low- and lowintermediate-risk prostate cancer: is there a dose effect? Front. Oncol. 1:49. doi: 10.3389/fonc.2011.00049

This article was submitted to Frontiers in Radiation Oncology, a specialty of Frontiers in Oncology.

Copyright (c) 2011 Katz, Santoro, Ashley and Diblasio. This is an open-access article distributed under the terms of the Creative Commons Attribution Non Commercial License, which permits noncommercial use, distribution, and reproduction in other forums, provided the original authors and source are credited. 